\title{
COMMENT
}

\section{Appetite for knowledge: curiosity and children's academic achievement}

\author{
Brenna Hassinger-Das ${ }^{1}$ and Kathy Hirsh-Pasek ${ }^{2,3}$ \\ Pediatric Research (2018) 84:323-324; https://doi.org/10.1038/s41390-018-0099-4
}

Curiosity is critical for the development of knowledge, even from the earliest of ages. From infants' motivation to explore their immediate physical environment to kindergarteners questioning why the sky is blue, curiosity drives our acquisition of new understandings about the wider world. Subject to many definitional debates, curiosity is both a state and a trait related to the need for new knowledge and the drive to explore to find it. ${ }^{1-3}$

In the current issue of Pediatric Research, Shah, Weeks, Richards, and Kaciroti examine the relations among kindergarten children's curiosity and their academic achievement in both reading and mathematics in the article "Early Childhood Curiosity and Kindergarten Reading and Math Academic Achievement." Using a large, representative sample of children enrolled in kindergarten in the United States, the authors found that higher levels of curiosity were associated with greater mathematics and reading achievement in kindergarten. Interestingly, this relation was not moderated by the biological sex of the children or measurements of their attention and persistence (effortful control). However, for children experiencing poverty, curiosity was more highly associated with reading and mathematics achievement than for children from higher socioeconomic backgrounds. Throughout their article, Shah and colleagues demonstrate the potential importance of curiosity for supporting children's academic achievement-and highlight the possibility that it may benefit children to participate in activities that foster their creativity in early childhood.

\section{WHAT IS CURIOSITY?}

And yet, the authors also waded into a $50+$ years long debate over the definition of curiosity. ${ }^{1-3}$ What is it? How do we measure it? As a trait, researchers have argued that curiosity involves personal characteristics, such as a readiness to try new activities and comfort with embracing the unexpected. ${ }^{1,3}$ Similar to many previous studies, Shah and colleagues examine trait curiosity and describe it as "characterized by the joy of discovery and the motivation to seek answers to what is unknown" (p. 4). Yet, measuring trait curiosity has proven to be very difficult; in fact, researchers have argued that there is often a mismatch between prevalent definitions of curiosity focusing on children's behaviors and the self-report and teacher/parent report measures that are used to capture them. ${ }^{4}$

These issues also affect the current study, since Shah and colleagues used a subset of five questions from the Preschool and
Kindergarten Behavioral Scales Second Edition (PKBS-2) to measure children's curiosity in kindergarten. To complete the measure, parents were instructed to indicate the frequency of the following behaviors observed in the previous three months on a 5point Likert scale (1, never to 5 , very often): likes to try new things, shows eagerness to learn new things, shows imagination in work and play, easily adjusts to a new situation, and appropriately uses a variety of words to describe feelings.

However, as a state, curiosity consists of emotions and behaviors that are triggered by specific contexts and situations. ${ }^{1,3}$ The benefits of attempting to measure state curiosity are more clear-cut; by understanding more about how to foster this type of curiosity, we may be able to develop interventions and strategies that can stimulate state curiosity in a variety of different ages and populations. At the same time, trait and state curiosity are not necessarily distinct from one another. Research has demonstrated that they are often highly correlated, ${ }^{1,5}$ which can add an additional wrinkle when thinking about how to define and measure various aspects of curiosity.

In the midst of these definitional struggles, Kidd and Hayden ${ }^{2}$ argue that there are, in fact, benefits to not having a strict definition of curiosity at this point in time. They state that beyond having a broad description, which they define as "a drive state for information" (p. 450), narrowing the definition will be too limiting for a field that is still trying to find its footing. Many researchers study similar concepts but use different terms-such as exploratory play, exploration, reinforcement learning, et cetera ${ }^{4,6,7}-$ which Kidd and Hayden argue must be integrated before a singular definition can be agreed upon.

Further, there is real question about how curiosity should be measured once the field agrees on a core definition. In this study, the authors chose to use parent report as the means for identifying curious children. While the attempt was a noble one with adequate internal consistency, this question deserves more scrutiny. It would be interesting to consider what a clean measure of the construct might have looked like if the study had not been limited by secondary data analysis. Perhaps Jirout and Klahr's ${ }^{4}$ measure of how children deal with uncertainty might provide a more straightforward assessment of the key predictor variable.

\section{WHY DOES CURIOSITY MATTER?}

Still, we must ask, "Why does curiosity matter?" Previous research has found that across the lifespan, curiosity relates to a wide

\footnotetext{
${ }^{1}$ Pace University - Psychology, 41 Park Row FI 13, New York, NY 10038, USA; ${ }^{2}$ Temple University - Psychology, Philadelphia, PA, USA and ${ }^{3}$ The Brookings Institution, Washington, DC, USA

Correspondence: Brenna Hassinger-Das (bhassingerdas@pace.edu)
}

Published online: 2 July 2018 
variety of factors - such as interest ${ }^{8,9}$ and job performance ${ }^{10}$-and it is one of the most valued traits of exemplary scientists. ${ }^{11}$

One crucial contribution of Shah and colleagues (this issue) is their investigation of the relations among curiosity and early academic outcomes. Similar to some previous research, ${ }^{12}$ Shah et al. present us with findings that provide a rationale for the possibility of designing interventions and strategies for increasing children's trait curiosity. If curiosity is related to achievement in both reading and mathematics - however minimally - then it may be in children's best interest to support their curiosity from an early age. The authors also included a measure of effortful control and suggest that curiosity is just as important as effortful control for kindergarten reading and mathematics performance.

Finally, Shah et al.'s finding regarding differences in curiosity's relation with academic achievement based on SES background is particularly interesting. They suggest that children experiencing poverty often live in environments with fewer resources, which might include fewer storybooks in the home or fewer opportunities to visit museums or other cultural activities, and this dearth of enrichment opportunities is the catalyst that pushes some children to seek out chances for learning and cognitive engagement. However, this finding could also represent that some children experiencing poverty seek out more certainty and less novelty, perhaps because they might prioritize safety over exploration-and thus their academic achievement does not increase at the same rate as their more curious peers.

\section{WHERE DO WE GO FROM HERE?}

With the field of curiosity research still developing, where do we go from here? While Shah and colleagues have provided new data regarding curiosity and its relation to children's academic success, more research is needed to further elucidate these connections. What specific behaviors drive these relations? What can we do to help foster these behaviors in children, especially in children experiencing poverty? Do these relations look different across varying cultural contexts? We look forward to future research that builds upon Shah and colleagues' work to continue to define curiosity, measure curiosity, and connect curiosity with other critical cognitive outcomes for children.

\section{ADDITIONAL INFORMATION}

Competing interests: The authors declare no competing interests.

Publisher's note: Springer Nature remains neutral with regard to jurisdictional claims in published maps and institutional affiliations.

\section{REFERENCES}

1. Grossnickle, E. M. Disentangling curiosity: dimensionality, definitions, and distinctions from interest in educational contexts. Educ. Psychol. Rev. 28, 23-60 (2016).

2. Kidd, C. \& Hayden, B. Y. The psychology and neuroscience of curiosity. Neuron $\mathbf{8 8}$, 449-460 (2015).

3. Loewenstein, G. The psychology of curiosity: a review and reinterpretation. Psychol. Bull. 116, 75-98 (1994).

4. Jirout, J. \& Klahr, D. Children's scientific curiosity: in search of an operational definition of an elusive concept. Dev. Rev. 32, 125-160 (2012).

5. Reio, T. G. Jr. \& Callahan, J. L. Affect, curiosity, and socialization-related learning: a path analysis of antecedents to job performance. J. Bus. Psychol. 19, 3-22 (2004).

6. Cahill-Solis, T. L. \& Witryol, S. L. Children's exploratory play preferences for four levels of novelty in toy constructions. Genet. Soc. Gen. Psychol. Monogr. 120, 393-408 (1994).

7. Sutton, R. S. \& Barto, A. G. Reinforcement Learning: An Introduction (MIT Press, Cambridge, MA, 1998).

8. Mussel, P. Epistemic curiosity and related constructs: lacking evidence of discriminant validity. Pers. Individ. Dif. 49, 506-510 (2010).

9. Schmitt, F. F. \& Lahroodi, R. The epistemic value of curiosity. Educ. Theory 58, 125-148 (2008).

10. Mussel, P. Introducing the construct curiosity for predicting job performance. J. Organ. Behav. 34, 453-472 (2012).

11. Pennock, R. T. \& Miller, J. D. Virtues of U.S. scientists guiding scientific practice. In Symposia Presented at the AAAS Annual Meeting, Washington, D.C. (2016).

12. Broussard, S. C. \& Garrison, M. E. B. The relationship between classroom motivation and academic achievement in elementary-school-aged children. Fam. Consum. Sci. Res. J. 33, 106-120 (2004). 